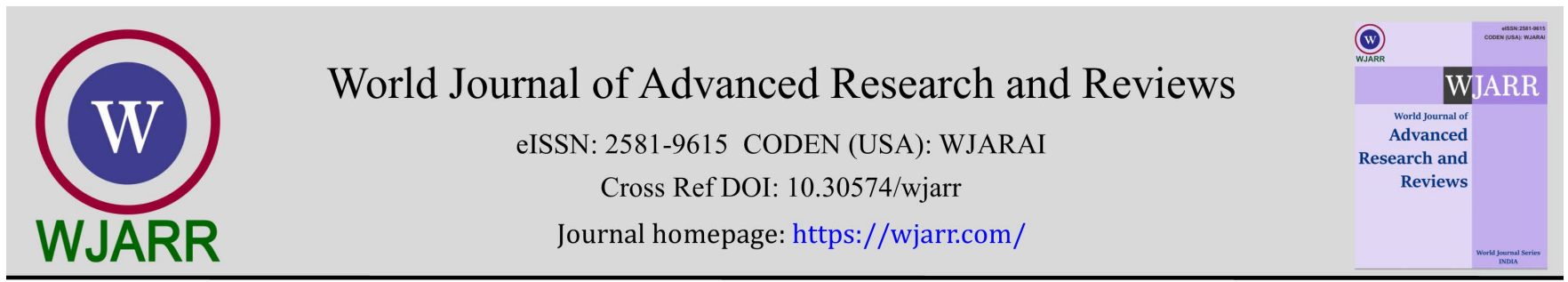

(RESEARCH ARTiCle)

Check for updates

\title{
Evaluate the effectiveness and safety of proton pump inhibitors (PPIs) in the treatment of upper GIT disorders
}

Ahmed Mousa Elgadi 1, Ahmed Hijazi Mahmoud 1, Azeldin fouzi Alabidi 1, Zinab Ali Albarghathi 1, Nouha Elmabrouk Mohammed 1, 2, Iman Elmahdi Mohamed 1, 2, Salma Abdelkerim Bukhatwa 1, 2 and Ali Ateia elmabsout $1,3, *$

${ }^{1}$ Faculty of Pharmacy, Libyan International Medical University, Benghazi, Libya.

${ }^{2}$ Department of Pharmacology and Toxicology, College of Pharmacy, University of Benghazi, Benghazi, Libya.

${ }^{3}$ Department of Nutrition, faculty of public health, University of Benghazi, Benghazi, Libya.

World Journal of Advanced Research and Reviews, 2022, 13(01), 027-037

Publication history: Received on 28 November 2021; revised on 01 January 2022; accepted on 03 January 2022

Article DOI: https://doi.org/10.30574/wjarr.2022.13.1.0755

\begin{abstract}
Introduction: Proton pump inhibitors (PPIs) are most prescribed medication classes and have similar efficacy between generic and brand names. PPIs are used for treatment upper GIT disorders. The aim of the present study was to evaluate the effectiveness and safety of proton pump inhibitors (PPIs).
\end{abstract}

Methods: A cross sectional study conducted randomly on pharmacies, patients and Doctors to collect a data regarding the effectiveness and safely use of PPI through predesigned questionnaire containing information about dosage, types, side effect, effectiveness and safety of PPIs. The collected data was analysis by using Chi-square for determine the significant differences at $\alpha<0.05$.

Result: The result of present study revealed numbers of points in which the questionnaire were intended for pharmacies, patients and doctors knowledge, effectiveness and safety of PPIs. The data gathered from pharmacy shown PPI dispensed without prescription $(P<0.05)$ in dose of $20 \mathrm{mg}$ of omeprazole and for treatment of gastritis, stomachache and on medication use $(P<0.05)$. No side effect or any problem, safe, and effective of PPIs was from patients seeking PPIs to the drug dispensers. Furthermore, questionnaire for patients whom seeking treatment shown some similarity to pharmacies answers, however lack the knowledge about side effect of PPIs, and PPIs withdraw among patients. PPIs was found to be used by patients due to the advices of friends $(P<0.05)$. The last part in this study was doctors involved in which some common similarity were also identified between doctors, patients and pharmacies responses. Although, Doctors responses were revealed that PPIs should be used by prescription in single dose of common types of PPIs $(P<$ $0.05)$.

Conclusion: Due to the short time use of PPIs have been reported. This study suggested that, even no side effect and highly effective of PPIs reported, the PPIs should be monitoring and use under prescription.

Keywords: PPIs; Patients; Pharmacies; Doctors; Effectiveness; Safety.

\section{Introduction}

Proton pump inhibitors (PPIs) have been identified in 1990s [1] and defined as class of drugs effect on lowering stomach acid production via irreversibly inhibiting the $\mathrm{H}^{+} / \mathrm{K}^{+}$ATPase proton pump of the stomach [2]. PPIs play significant role

\footnotetext{
* Corresponding author: Ali Ateia elmabsout

Faculty of Pharmacy, Libyan International Medical University, Benghazi, Libya.
}

Copyright (C) 2022 Author(s) retain the copyright of this article. This article is published under the terms of the Creative Commons Attribution Liscense 4.0. 
in the alleviated of Helicobacter pylori infection and also in the deterrence of upper gastrointestinal tract disorders, ulcers and bleeding in patients under antiplatelet therapy and/or non-steroidal anti-inflammatory drugs [2]. Furthermore, the medical options for the management of gastrointestinal reflex disease include antacids, histamine-2 receptor antagonists (H2RAs), and PPIs. PPIs treatment are consistently demonstrated to have higher healing response rates and lesser relapse rates in remedy of erosive esophagitis than H2RAs or placebo [3].

Currently, proton pump inhibitors (PPIs) is considered among the most commonly prescribed medications [4]. During the last decades, PPIs enhances the optimizing the healthcare community worldwide regarding its safety and effectiveness profile $[5,6]$. Though, the part of effectiveness remains true, disquiets have been arise regarding the outcome of long term use of PPIs and the serious adverse effects it may rises. The long term use of PPIs are associated with increased risk for gastric cancer, dementia, diarrhea pneumonia, increased gastric infection, gastric neuroendocrine tumor, hypomagnesemia, colon cancer, spontaneous bacterial peritonitis and hepatic encephalopathy and bacteria overgrowth of small intestine $[7,8]$.

In several studies, reported that improving the gastrointestinal function, ulcer, and GERD with PPIs than with H2RAs or placebo [8-10]. Additionally, the cumulative incidence has been found in healing rate irrespective of treatment duration among PPIs users (84\%) as compared to H2RAs (52\%) and placebo (28\%) [11]. Furthermore, A comparison between on-demand PPI therapy to continuous PPIs treatment result in patient satisfaction was no differences to on-demand PPI therapy in patients with non-erosive reflux disease [12]. However, on-demand PPIs therapy is not approved by FDAfor this patient population [12]. The single therapy with a PPI is not effective in eradicating $H$ pylori infection. Therefore,, the addition of a PPIs to a combination of antibiotics improves eradication rates compared to those achieved with antibiotics alone $[13,14]$. Due to lack of information if PPIs is safe and effectives among patients, and pharmacies and doctor opinion related PPIs used. Sacred data was found in the literature in which evaluated of safety and effectiveness of PPIs through direct interview to gathers enough background of PPIs side effect, safe, and effectiveness. The aims of the study is to evaluate the safety, possible side effect and effectiveness of proton pump inhibitors (PPIs) in terms of symptom resolution and relieve of upper GIT disorders.

\section{Material and methods}

\subsection{Study designed and sample size}

A Cross sectional survey conducted from beginning of November 2020 to the end of March 2021 on randomly selected patients suffering from upper GIT disorder visiting doctors, a doctors and pharmacies for receiving PPI in Benghazi city, Libya.

The sample in this study were selected randomly and divided into three categories in which questions intending for interview doctors, patients or drug dispensers (pharmacist)

The sample of this study comprised 83 Patients, 63 Doctors and 117 Pharmacies.

- Patients in this study whom seeking medical remedy for any chronic disease recruited from clinics and hospitals.

- Pharmacies: questionnaires were intended for the people who dispense the drugs in the pharmacies for PPI effectiveness and safety.

- Doctors: whom in charge for patient's treatment in clinics and hospitals.

\subsection{Questionnaires}

Pre-designed questionnaires was validity in which contain number of questions related to personal information, safety and effectiveness of PPI , types of PPI, side effect, dosages of PPI , frequent uses, purpose of PPI used, and knowledge of PPI withdraw suddenly.

\subsection{Ethical consideration}

This study was approval by the local Ethics Committee of the Libyan international medical university (LIMU). Informed written consent was obtained through a consent form that was given to the participants along with the questionnaire. 


\subsection{Data analysis}

The data from the questionnaires was entered using Excel. Data set was exported to SPSS v.22 and Epi-info for complete analysis. Statistical analysis was carried out for the complete sample which were created according to measurements in which frequencies and percentages were used. To determine the differences regarding each categorical variable in the groups, Chi-square test was performed. $\mathrm{p} \leq 0.05$ was considered to be statistically significant.

\section{Results}

In the table 1 , no age specified has been reported by drug dispensers, and the interviewed with patients attended clinics and hospitals found that $41 \%$ of patients fall under age groups $24-40$ years old were use PPIs, followed by age groups between 18-25 years old 30.1\%. Furthermore, the doctors reported that, the age of patients most common attended to the clinic and seeking medical remedy were found those age groups between $26-40$ years old $79.4 \%$. The male patients in three categories of studied samples were found mostly seeking PPIs than female.(Figure 1).

Table 1 Ages distribution of the subjects from drugs dispenser, patients, and doctors.

\begin{tabular}{|l|l|c|c|c|}
\hline \multicolumn{2}{|c|}{ Age categories of patients } & N & N \% & P values \\
\hline \multirow{4}{*}{$\begin{array}{l}\text { Ages of patients recurrent buy PPI from pharmacies } \\
\text { (Reporting of drugs dispensers) }\end{array}$} & Not defined & 117 & $100.0 \%$ & \\
\hline & Total & 117 & $100.0 \%$ & \\
\hline \multirow{4}{*}{ Age of patients participate in the study } & $18-25$ years & 25 & $30.1 \%$ & \\
\cline { 2 - 5 } & $26-40$ years old & 34 & $41.0 \%$ & \\
\cline { 2 - 5 } & $41-60$ years old & 22 & $26.5 \%$ & \\
\cline { 2 - 5 } & Older than 60 years & 2 & $2.4 \%$ & \\
\hline & Total & 83 & $100.0 \%$ & \\
\hline \multirow{4}{*}{$\begin{array}{l}\text { Age of patients attended the clinic for visiting doctor } \\
\text { (ages reported by doctors) }\end{array}$} & $18-25$ years & 7 & $11.1 \%$ & \\
\cline { 2 - 5 } & $26-40$ years old & 50 & $79.4 \%$ & 0.000 \\
\cline { 2 - 5 } & $41-60$ years old & 6 & $9.5 \%$ & \\
\cline { 2 - 5 } & Total & 63 & $100.0 \%$ & \\
\hline
\end{tabular}

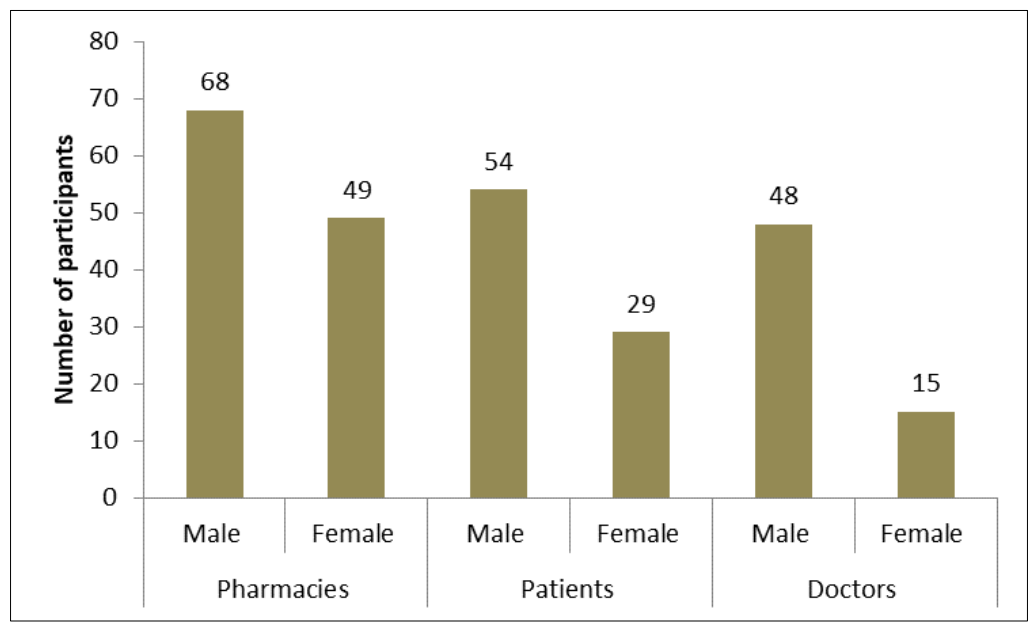

Figure 1 Gender distribution reported by pharmacists (drug dispensers), patients, Doctors 


\subsection{Analysis the data collected from drug dispenser (Pharmacies) regarding PPI safety and affectivity}

The survey in this study includes 117 pharmacies in which 117 questionnaires were collected. The data present in table 2 revealed that drug dispensers was not only dispense by the qualified person (pharmacists) $38.5 \%$ but this job also participate by medical doctor, dentist and public health professional,. Significant high number of patients $(P=0.000)$ were used PPIs by drug dispensers by their own experiences (76.1\%). Furthermore, it was found that no differences in PPIs types dispensed by drugs dispensers. The reason beyond the drug dispensers prescribe the PPIs were due to their effective and safety $41 \%$ and $41.9 \%$ respectively. The question regarding most common types of PPIs prescribed by doctor shown that Omeprazole was the significant prescribed ( $P=0.000$ ). The most common dose of PPIs were consumed by patients seeking PPI was $20 \mathrm{mg}(P=0.00)$. The data in table 2 also revealed that the drug dispensers prescribe the PPIs for treatment of both Gastritis, stomachache and on medication uses $(P=0.001)$.

The table 3 , shown that approximately $72.6 \%$ of patients recurring improve after use the PPI $(P=0.000)$. Regarding the side effect reported by drug dispensers on PPIs users revealed that no any side effect in which represent $100 \%$ and PPIs were shown effectiveness and safely in about $29.1 \%$ and $43.6 \%$ respectively and the rest $27.4 \%$ of the customers use PPIs were found no improvement .

Table 2 information gathering from the drug dispenser at pharmacies on PPI uses.

\begin{tabular}{|c|c|c|c|c|}
\hline & & $\mathbf{N}$ & $\mathrm{N} \%$ & P values \\
\hline \multirow{5}{*}{$\begin{array}{l}\text { Qualification of drugs } \\
\text { dispensers }\end{array}$} & Pharmacist & 45 & $38.5 \%$ & \\
\hline & Medical doctor & 10 & $8.5 \%$ & \\
\hline & dentist & 37 & $31.6 \%$ & \\
\hline & Public health & 25 & $21.4 \%$ & \\
\hline & Total & 117 & $100.0 \%$ & \\
\hline \multirow{3}{*}{ Dispense of PPIs } & With prescription & 28 & $23.9 \%$ & \\
\hline & Without Prescription & 89 & $76.1 \%$ & 0.000 \\
\hline & Total & 117 & $100.0 \%$ & \\
\hline \multirow{3}{*}{$\begin{array}{l}\text { Most common PPIs } \\
\text { prescribed by doctor }\end{array}$} & Omeprazole & 74 & $63.2 \%$ & 0.000 \\
\hline & Esomeprazole (Nexium) & 43 & $36.8 \%$ & \\
\hline & Total & 117 & $100.0 \%$ & \\
\hline \multirow{3}{*}{$\begin{array}{l}\text { If PPIs is not } \\
\text { prescribed which } \\
\text { PPIs is dispensed }\end{array}$} & Omeprazole & 63 & $53.8 \%$ & \\
\hline & Esomeprazole (Nexium) & 54 & $46.2 \%$ & \\
\hline & Total & 117 & $100.0 \%$ & \\
\hline \multirow{4}{*}{$\begin{array}{l}\text { The reason for choose } \\
\text { and dispense the } \\
\text { particular } \\
\text { PPIs are due to }\end{array}$} & Cheap & 20 & $17.1 \%$ & \\
\hline & Effective & 48 & $41.0 \%$ & \\
\hline & safe & 49 & $41.9 \%$ & \\
\hline & Total & 117 & $100.0 \%$ & \\
\hline \multirow{4}{*}{$\begin{array}{l}\text { Dose of PPIs } \\
\text { dispensed }\end{array}$} & $10 \mathrm{mg}$ & 19 & $16.2 \%$ & \\
\hline & $20 \mathrm{mg}$ & 73 & $62.4 \%$ & 0.00 \\
\hline & $40 \mathrm{mg}$ & 25 & $21.4 \%$ & \\
\hline & Total & 117 & $100.0 \%$ & \\
\hline \multirow{6}{*}{$\begin{array}{l}\text { Dispensed PPIs to the } \\
\text { patient for treatment } \\
\text { of }\end{array}$} & Ulcer & 1 & $0.9 \%$ & \\
\hline & H pylori & 5 & $4.3 \%$ & \\
\hline & Ulcer and gastritis & 10 & $8.5 \%$ & \\
\hline & Gastritis, stomachache and on medication use & 76 & $65.0 \%$ & 0.001 \\
\hline & Gastritis and $\mathrm{H}$ pylori & 25 & $21.4 \%$ & \\
\hline & Total & 117 & $100.0 \%$ & \\
\hline
\end{tabular}

Chi-square test was performed within groups and considered significant at $\alpha<0.05$. 
Table 3 information gathering from the drug dispenser at pharmacies on PPI uses.

\begin{tabular}{|c|c|c|c|c|}
\hline & & $\mathbf{N}$ & N \% & $P$ values \\
\hline \multirow{2}{*}{ Know the side effect of PPIs } & Yes & 117 & $100.0 \%$ & \\
\hline & Total & 117 & $100.0 \%$ & \\
\hline \multirow{3}{*}{ Time of taken PPIs } & Before breakfast & 61 & $52.1 \%$ & \\
\hline & Before breakfast and dinner & 56 & $47.9 \%$ & \\
\hline & Total & 117 & $100.0 \%$ & \\
\hline \multirow{3}{*}{$\begin{array}{l}\text { The patients improved after } \\
\text { use PPIs }\end{array}$} & Yes & 85 & $72.6 \%$ & 0.000 \\
\hline & No & 32 & $27.4 \%$ & \\
\hline & Total & 117 & $100.0 \%$ & \\
\hline \multirow{4}{*}{$\begin{array}{l}\text { Drug dispenser asked the } \\
\text { patients once improved for } \\
\text { PPIs }\end{array}$} & Non improved & 32 & $27.4 \%$ & \\
\hline & Effectiveness & 34 & $29.1 \%$ & \\
\hline & Safely & 51 & $43.6 \%$ & \\
\hline & Total & 117 & $100.0 \%$ & \\
\hline \multirow{2}{*}{$\begin{array}{l}\text { If Patients complain on any } \\
\text { side effect }\end{array}$} & No & 117 & $100.0 \%$ & \\
\hline & Total & 117 & $100.0 \%$ & \\
\hline \multirow{2}{*}{$\begin{array}{l}\text { Option for trial after the } \\
\text { failure of first PPIs }\end{array}$} & No failure & 117 & $100.0 \%$ & \\
\hline & Total & 117 & $100.0 \%$ & \\
\hline \multirow{2}{*}{ The patients used same PPIs } & Yes & 117 & $100.0 \%$ & \\
\hline & Total & 117 & $100.0 \%$ & \\
\hline
\end{tabular}

Chi-square test was performed within groups and considered significant at $\alpha<0.05$.

\subsection{Analysis the data collected from patients regarding PPIs safety and affectivity:}

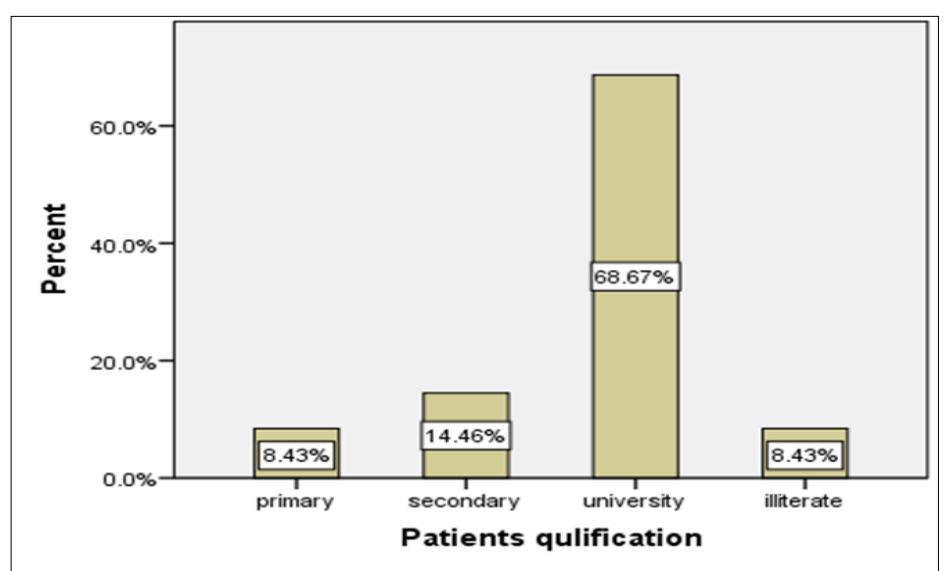

Figure 2 Qualifications of the patients involve in the study and use PPIs

The patients in this study recruited from hospital and/or clinics seeking treatment for chronic diseases. In the figure 2 , about tow third of patients have high levels of educations (university levels) followed by secondary education levels $(14.46 \%)$ while the other education levels being the least include primary and illiterate (8.43\%) for each. There was no significant differences between patient's answers for PPIs can purchasing with or without prescription (Table 4). Omeprazole was significantly highly consumed by patients than other types of PPIs $(P<0.05)$. The patients reported that used PPI due to their friend advices. Furthermore, the reason for selected particular type of PPI by patients was due to number of factors include prescribed by doctors, effective and as well as cheap. The significant dose of PPIs 
consumed by patients was $20 \mathrm{mg}$ twice a day mainly used before main meals. $(P<0.05)$ (Table 5). The question regarding the purpose of using PPI, the most respondent was for treatment of GERD followed by ulcer and stomachache $32.5 \%, 21.7 \%$ and $18.1 \%$ respectively. Effectiveness of PPI has been reported by patients through pain disappear after using of PPI $(P<0.05)$, no side effect $(P<0.05)$ and significant numbers of patients were not have knowledge in case of withdraw PPI should be done gradually $(P<0.05)$

Table 4 information gathering from the patients on PPIs uses.

\begin{tabular}{|c|c|c|c|c|}
\hline & & $\mathbf{N}$ & N \% & $P$ values \\
\hline \multirow{3}{*}{ Patient Taken PPIs } & With prescription & 44 & $53.0 \%$ & \\
\hline & Without prescription & 39 & $47.0 \%$ & \\
\hline & Total & 83 & $100.0 \%$ & \\
\hline \multirow{5}{*}{ Most common PPIs used } & Omeprazole & 53 & $63.9 \%$ & 0.001 \\
\hline & Pantoprazole & 3 & $3.6 \%$ & \\
\hline & Esomeprazole & 16 & $19.3 \%$ & \\
\hline & Omeprazole+ Pantoprazole+ Esomeprazole & 11 & $13.3 \%$ & \\
\hline & Total & 83 & $100.0 \%$ & \\
\hline \multirow{3}{*}{$\begin{array}{l}\text { Used PPIs under advice } \\
\text { from }\end{array}$} & Friends & 50 & $60.2 \%$ & 0.043 \\
\hline & Pharmacists (drug dispensers) & 33 & $39.8 \%$ & \\
\hline & Total & 83 & $100.0 \%$ & \\
\hline \multirow{5}{*}{$\begin{array}{l}\text { The reason for use the } \\
\text { particular type of PPIs }\end{array}$} & cheap & 5 & $6.0 \%$ & \\
\hline & Got prescription from doctor & 29 & $34.9 \%$ & \\
\hline & Effective & 35 & $42.2 \%$ & \\
\hline & Altogether & 14 & $16.9 \%$ & \\
\hline & Total & 83 & $100.0 \%$ & \\
\hline \multirow{6}{*}{ Dose of PPIs } & $10 \mathrm{mg}$ & 11 & $13.3 \%$ & \\
\hline & $20 \mathrm{mg}$ & 47 & $56.6 \%$ & 0.003 \\
\hline & $30 \mathrm{mg}$ & 9 & $10.8 \%$ & \\
\hline & $40 \mathrm{mg}$ & 12 & $14.5 \%$ & \\
\hline & $10+20 \mathrm{mg}$ & 4 & $4.8 \%$ & \\
\hline & Total & 83 & $100.0 \%$ & \\
\hline \multirow{8}{*}{ Frequency of use of PPIs } & Once & 29 & $34.9 \%$ & \\
\hline & Twice & 51 & $61.4 \%$ & 0.04 \\
\hline & Triple & 3 & $3.6 \%$ & \\
\hline & Total & 83 & $100.0 \%$ & \\
\hline & Before breakfast & 26 & $31.3 \%$ & \\
\hline & When pain arises & 3 & $3.6 \%$ & 0.001 \\
\hline & Before main meals & 54 & $65.1 \%$ & \\
\hline & Total & 83 & $100.0 \%$ & \\
\hline
\end{tabular}


Table 5 information gathering from the patients on PPI uses.

\begin{tabular}{|c|c|c|c|c|}
\hline & & $\mathbf{N}$ & $\mathrm{N} \%$ & $P$ values \\
\hline \multirow{7}{*}{ Purpose for using PPIs is for treatment of } & GERD & 27 & $32.5 \%$ & 0.04 \\
\hline & Ulcer & 18 & $21.7 \%$ & \\
\hline & Gastritis & 6 & $7.2 \%$ & \\
\hline & Stomachache & 15 & $18.1 \%$ & \\
\hline & H pylori & 9 & $10.8 \%$ & \\
\hline & Assist for digestions & 8 & $9.6 \%$ & \\
\hline & Total & 83 & $100.0 \%$ & \\
\hline \multirow{6}{*}{ Feeling and outcome after use of PPIs } & Pain disappeared & 50 & $60.2 \%$ & 0.00 \\
\hline & Reduced HCL & 11 & $13.3 \%$ & \\
\hline & Eradicated H pylori & 2 & $2.4 \%$ & \\
\hline & GERD disappear & 10 & $12.0 \%$ & \\
\hline & Ulcer remedy & 10 & $12.0 \%$ & \\
\hline & Total & 83 & $100.0 \%$ & \\
\hline \multirow{3}{*}{$\begin{array}{l}\text { Patients Knowledge about } \\
\text { The side effect of using PPIs }\end{array}$} & Yes & 27 & $32.5 \%$ & \\
\hline & No & 56 & $67.5 \%$ & 0.001 \\
\hline & Total & 83 & $100.0 \%$ & \\
\hline \multirow{9}{*}{ Health problems associated with use PPIs } & Non & 48 & $57.8 \%$ & 0.000 \\
\hline & Headache & 9 & $10.8 \%$ & \\
\hline & Nausea & 5 & $6.0 \%$ & \\
\hline & Diarrhea & 10 & $12.0 \%$ & \\
\hline & Fatigue & 6 & $7.2 \%$ & \\
\hline & Dizziness & 1 & $1.2 \%$ & \\
\hline & Constipation & 1 & $1.2 \%$ & \\
\hline & Flatulence & 3 & $3.6 \%$ & \\
\hline & Total & 83 & $100.0 \%$ & \\
\hline \multirow{8}{*}{ Duration of using PPIs } & $<$ one week & 7 & $8.4 \%$ & \\
\hline & 1-2 weeks & 24 & $28.9 \%$ & \\
\hline & 3-4 weeks & 25 & $30.1 \%$ & \\
\hline & One month & 9 & $10.8 \%$ & \\
\hline & 1-6 months & 7 & $8.4 \%$ & \\
\hline & 1 year & 1 & $1.2 \%$ & \\
\hline & Forever & 10 & $12.0 \%$ & \\
\hline & Total & 83 & $100.0 \%$ & \\
\hline \multirow{3}{*}{ Withdraw or stop using PPI should be gradually } & Yes & 16 & $19.3 \%$ & \\
\hline & No & 67 & $80.7 \%$ & 0.000 \\
\hline & Total & 83 & $100.0 \%$ & \\
\hline
\end{tabular}

Chi-square test was performed within groups and considered significant at $\alpha<0.05$.

\subsection{Analysis the data collected from Doctors regarding PPIs safety and affectivity:}

In the next step, questionnaire was designs and intended for Doctors answers include many points were significant responded, such as PPIs should be given to the patients by prescription, Doctors prescribe different types of PPIs, the particular PPIs given to the patients based on effectiveness $49.2 \%$ followed by both cheap and effectiveness $38.1 \%$. Furthermore, the doctors noticed the effectiveness and safety of PPI through high treatment outcome reported by patients 74.6\% $(P<0.05)$ and effectiveness of PPIs were the first priorities to the patients (Table 6 and 7). 
Table 6 Doctors opinion regarding use of PPIs.

\begin{tabular}{|c|c|c|c|c|}
\hline & & $\mathbf{N}$ & N \% & $P$ values \\
\hline \multirow{2}{*}{$\begin{array}{l}\text { PPIs should be dispensed by } \\
\text { prescription not as OTC }\end{array}$} & Yes & 63 & $100.0 \%$ & \\
\hline & Total & 63 & $100.0 \%$ & \\
\hline \multirow{2}{*}{$\begin{array}{l}\text { Doctors knowledge } \\
\text { regarding PPIs side effect }\end{array}$} & Yes & 63 & $100.0 \%$ & \\
\hline & Total & 63 & $100.0 \%$ & \\
\hline \multirow{6}{*}{$\begin{array}{l}\text { PPIs most common } \\
\text { prescribed }\end{array}$} & Omeprazole & 3 & $4.8 \%$ & \\
\hline & Esomeprazole & 22 & $34.9 \%$ & \\
\hline & Omeprazole, Pantoprazole and Esomeprazole & 15 & $23.8 \%$ & \\
\hline & Omeprazole and Esomeprazole & 17 & $27.0 \%$ & \\
\hline & Pantoprazole and Esomeprazole & 6 & $9.5 \%$ & \\
\hline & Total & 63 & $100.0 \%$ & \\
\hline \multirow{5}{*}{$\begin{array}{l}\text { Reason for choice the } \\
\text { particular type of PPIs }\end{array}$} & cheap & 5 & $7.9 \%$ & \\
\hline & Safe & 3 & $4.8 \%$ & \\
\hline & Effective & 31 & $49.2 \%$ & \\
\hline & Cheap and effective & 24 & $38.1 \%$ & \\
\hline & Total & 63 & $100.0 \%$ & \\
\hline \multirow{4}{*}{ Dose of PPIs prescribed } & $10 \mathrm{mg}$ & 11 & $17.5 \%$ & \\
\hline & $20 \mathrm{mg}$ & 47 & $74.6 \%$ & 0.001 \\
\hline & $40 \mathrm{mg}$ & 5 & $7.9 \%$ & \\
\hline & Total & 63 & $100.0 \%$ & \\
\hline \multirow{3}{*}{ Frequency of use PPIs } & Once & 36 & $57.1 \%$ & \\
\hline & Twice & 27 & $42.9 \%$ & \\
\hline & Total & 63 & $100.0 \%$ & \\
\hline
\end{tabular}

Chi-square test was performed within groups and considered significant at $\alpha<0.05$.

Table 7 Doctors opinion regarding use of PPIs.

\begin{tabular}{|c|c|c|c|c|}
\hline & & $\mathbf{N}$ & N \% & P values \\
\hline \multirow{3}{*}{$\begin{array}{l}\text { The time for patients } \\
\text { to take PPIs }\end{array}$} & Before breakfast & 36 & $57.1 \%$ & \\
\hline & Before main meals & 27 & $42.9 \%$ & \\
\hline & Total & 63 & $100.0 \%$ & \\
\hline \multirow{7}{*}{$\begin{array}{l}\text { Prescribed PPIs for } \\
\text { Treatment of }\end{array}$} & GERD & 5 & $7.9 \%$ & \\
\hline & GERD, gastritis, H pylori and for assist digestion & 16 & $25.4 \%$ & \\
\hline & GERD and Gastritis & 11 & $17.5 \%$ & \\
\hline & GERD, gastritis, H pylori & 21 & $33.3 \%$ & \\
\hline & For use of medications & 10 & $15.9 \%$ & \\
\hline & Total & 63 & $100.0 \%$ & \\
\hline & Pain gone & 47 & $74.6 \%$ & 0.000 \\
\hline
\end{tabular}




\begin{tabular}{|c|c|c|c|c|}
\hline \multirow{2}{*}{$\begin{array}{l}\text { Outcome of PPIs } \\
\text { treatment through }\end{array}$} & GERD disappear & 16 & $25.4 \%$ & \\
\hline & Total & 63 & $100.0 \%$ & \\
\hline \multirow{2}{*}{$\begin{array}{l}\text { Any side effect } \\
\text { reported by patients }\end{array}$} & No & 63 & $100.0 \%$ & \\
\hline & Total & 63 & $100.0 \%$ & \\
\hline \multirow{4}{*}{$\begin{array}{l}\text { Frequent prescribed } \\
\text { PPIs due to }\end{array}$} & Effectiveness & 49 & $77.8 \%$ & 0.000 \\
\hline & Cost & 1 & $1.6 \%$ & \\
\hline & Experiences & 13 & $20.6 \%$ & \\
\hline & Total & 63 & $100.0 \%$ & \\
\hline
\end{tabular}

Chi-square test was performed within groups and considered significant at $\alpha<0.05$.

\section{Discussion}

Proton pump inhibitors initially intending for the treatment of esophagitis, and then subsequently been extended for treatment of other conditions of the upper GI tract [15].

The present study revealed a number of points in which this study include data from pharmacies, patients seeking treatment for chronic disease and also doctors.

\subsection{Data collected form pharmacies}

The data collected from pharmacies were unpredicted particular in many pointes include the people in pharmacies were not qualified persons in which the majorities were not pharmacists and professional persons this is could be why the question for PPIs can be sold without prescription given high responses (76.1\%). FDA distributed a final law on September 12, 1980, launching a three-year trial period during which PPIs must be described with each new prescription for 10 specific drugs or drug classes. Involved are the drugs cimetidine, clofibrate, propoxyphene, phenytoin, warfarin, digoxin, and methoxsalen, and the drug class's ampicillins, benzodiazepines, and thiazides [16]. The result of this study also indicated that omeprazole and $20 \mathrm{mg}$ as most common were dispense to the patients via drug dispensers this may be due to the reasons mentioned elsewhere in which the increase in PPIs use may be due to policy, prescriber, or patient factors, including increased availability of both branded and generic PPIs [17].

Based on several reported, there has been recent extensive media attention given to the safety of PPIs [15]. In the previous studies were shown PPIs was intended for use for many upper GIT disorder include Barrett esophagus, gastroesophageal reflux disease, dyspepsia, eosinophilic esophagitis, and treatment of Helicobacter pylori infection and in the deterrence of upper gastrointestinal tract ulcers and bleeding among patients undertaking antiplatelet therapy and/or non-steroidal anti-inflammatory drugs $[15,18]$ and for some medication use [16]. Similarly has been found in this study in which Gastritis, stomachache and on medication use were reported by drug dispensers. The information gathering from pharmacies also indicated PPIs were safe and effective and no side effect reported among users and this due to PPI used for short time in this study. This finding was disagrees with a number of studies regarding safety and the side effect in which many studies found that PPIs has tremendous effects on the health when in use in long term [1921]. However, therapeutic effectiveness has been found from the pharmacies once dispense the PPIs through patients responses for what feeling after used PPIs.

\subsection{Data collected form patients}

Some data collected from patients were similar to the data from pharmacies include most common PPIs used, dosages, PPIs used for treatment of GERD, time of use of PPIs, safety, effectiveness. But it seemed that among patients, the used of PPI due to advices of friends and this was not surprising own to similar where also obtained from the study carried out by Ali et al [15]. Furthermore, the patients have low knowledge about gradually withdraw of PPIs and their side effects. PPIs should be abrupt gradually due to withdrawal from PPIs (proton pump inhibitors) can lead to severe rebound acid secretion, a complication that can force users to become dependent on them. In additions, the patients mentioned that use PPIs can be twice a day and this could be dependent on the severity of upper GIT disorders and this intake also be safe for use [22].

\subsection{Data collected from Doctors}

Similarly were also obtained answers from doctors by which the result of PPIs safety, effectiveness, side effect, and doses were similar to those responses from patients and pharmacies. However, the doctors were agree with FDA rules 
[16] in which PPIs should not be given as OTC (prescription only). The answers regarding number of PPI dose per day was present with slightly higher response as single dose but was not statistically significant. Overall, the data collected in this study revealed that PPI was generally safe, effective, being with no side effect, in single dose of any types of PPI used mainly before main meals. As with all other drugs, PPIs should be prescribed in the lowest effective doses and only continued for as long as necessary.

\section{Conclusion}

The present study revealed that, age significant use of PPIs in which the male higher than female. The drug dispensers were found have different and prescribe the PPIs without prescriptions, in dose $20 \mathrm{mg}$ of omeprazole for treatment of Gastritis, stomachache and on medication use. PPIs were found Effective and safe to the patients and no side effect have been reported. The significant numbers of patients were seeking medical remedy for treatment of GERD and were where used PPIs through advices of friends. The last part in this survey was doctors responses in which reported that PPIs should not be given to the patients without prescription, no particular of PPIs over the other to be choice, the most dose reported was $20 \mathrm{mg}$, PPIs prescribed to the patients based on effectiveness and both cheap and effectiveness, and the effectiveness of PPIs known through no pain raised after use. Altogether the data in this study suggested that, even no side effect and highly effective of PPIs reported in this study should be monitoring and PPIs should be use under prescription.

\section{Compliance with ethical standards}

\section{Acknowledgments}

We grateful to all patients participate in the study.

\section{Disclosure of conflict of interest}

No conflict of interest.

\section{Statement of informed consent}

This study was approval by the local Ethics Committee of the Libyan international medical university (LIMU). The study was done through an interview of the participants and informed written consent was obtained through a consent form that was given to the participants along with the questionnaire.

\section{References}

[1] Katz PO, Gerson LB, Vela MF. Guidelines for the diagnosis and management of gastroesophageal reflux disease. Am J Gastroenterol. 2013; 108(3): 308-328.

[2] Gerson LB, Mitra S, Bleker WF, Yeung P. Control of intra-oesophageal pH in patients with Barrett's oesophagus on omeprazole-sodium bicarbonate therapy Aliment Pharmacol Ther. 2012; 35(7): 803-809.

[3] Singh S, Sharma AN, Murad MH, et al. Central adiposity is associated with increased risk of esophageal inflammation, metaplasia, and adenocarcinoma: a systematic review and meta-analysis. Clin Gastroenterol Hepatol. 2013; 11(11): 1399-1412.e7.

[4] Bruzzi P. Non-drug industry funded research. BMJ. 2008; 336: 1-2.

[5] Savarino V, Di Mario F, Scarpignato C. Proton pump inhibitors in GORD An overview of their pharmacology, efficacy and safety. Pharmacol Res. 2009; 59: 135-153.

[6] Wan Q-Y, Wu X-T, Li N, Du L, Zhou Y.Long-term proton pump inhibitors use and risk of gastric cancer: a metaanalysis of 926386 participants. Gut. 2019; 68: 762-764.

[7] Garca Rodrguez LA, Martn-Pérez M, Hennekens CH, Rothwell PM, Lanas A. Bleeding risk with long-term low-dose aspirin: a systematic review of observational studies. PLoS One. 2016; 11(8): e0160046.

[8] Lavie CJ, Howden CW, Scheiman J, Tursi J. Upper gastrointestinal toxicity associated with long-term aspirin therapy: consequences and prevention. Curr Probl Cardiol. 2017; 42(5): 146-164. 
[9] Neumann I, Letelier LM, Rada G, et al. Comparison of different regimens of proton pump inhibitors for acute peptic ulcer bleeding. Cochrane Database Syst Rev. 2013; (6): CD007999.

[10] Sachar H, Vaidya K, Laine L. Intermittent vs continuous proton pump inhibitor therapy for high-risk bleeding ulcers: a systematic review and meta-analysis. JAMA Intern Med. 2014; 174(11): 1755-1762.

[11] Lacy BE, Weiser KT, Kennedy AT, Crowell MD, Talley NJ. Functional dyspepsia: the economic impact to patients. Aliment Pharmacol Ther. 2013; 38(2): 170-177.

[12] Moayyedi PM, Lacy BE, Andrews CN, Enns RA, Howden CW, Vakil N. ACG and CAG Clinical Guideline: management of dyspepsia. Am J Gastroenterol. 2017; 112(7): 988-1013.

[13] Schubert ML, Peura DA. Control of gastric acid secretion in health and disease. Gastroenterology. 2008; 134: 1842-1860.

[14] Canani RB, Terrin G.Gastric acidity inhibitors and the risk of intestinal infections. Curr Opin Gastroenterol. 2010; 26: 31-35.

[15] Ali Khan M, Howden CW. The Role of Proton Pump Inhibitors in the Management of Upper Gastrointestinal Disorders. Gastroenterol Hepatol (N Y). 2018; 14(3): 169-175.

[16] Greenberg RB. Institutional pharmacists' guide to complying with PPI regulations. Am J Hosp Pharm. Dec 1980; 37(12): 1656-9.

[17] Carter JH, Sketris IS, Tamim H, Levy AR, Langley JM. Determining proton pump inhibitor prescription dispensing patterns and adherence to STOPP criteria for Nova Scotia Seniors Pharmacare Program beneficiaries. J Popul Ther Clin Pharmacol. 2019. 26(4): e37-e53; 27.

[18] Jiang M, Chen P, Gao Q: Systematic Review and Net-Work Meta-Analysis of Upper Gastrointestinal Hemorrhage Interventions. Cell Physiol Biochem. 2016; 39: 2477-2491.

[19] Jaynes M, Kumar AB. The risks of long-term use of proton pump inhibitors: a critical review. Ther Adv Drug Saf. 2018; 10: 2042098618809927.

[20] Seto CT, Jeraldo P, Orenstein R, et al. prolonged use of a proton pump inhibitor reduces microbial diversity: implications for Clostridium difficile susceptibility. Microbiome. 2014; 2: 42.

[21] Haenisch B, von Holt K, Wiese B, et al. Risk of dementia in elderly patients with the use of proton pump inhibitors. Eur Arch Psychiatry Clin Neurosci 2015; 265: 419-428.

[22] Abbas MK, Zaidi ARZ, Robert CA, Thiha S, Malik BH. The Safety of Long-term Daily Usage of a Proton Pump Inhibitor: A Literature Review. Cureus. 2019; 11(9): e5563. 